Kathrin Yen • Martin Sonnenschein • Michael J. Thali •

Christof Ozdoba · Joachim Weis · Karin Zwygart •

Emin Aghayev $\cdot$ Christian Jackowski •

Richard Dirnhofer

\title{
Postmortem Multislice Computed Tomography and Magnetic Resonance Imaging of odontoid fractures, atlantoaxial distractions and ascending medullary edema
}

Received: 15 June 2004 / Accepted: 4 November 2004 / Published online: 12 January 2005

(C) Springer-Verlag 2005

\begin{abstract}
Non-invasive imaging methods are increasingly entering the field of forensic medicine. Facing the intricacies of classical neck dissection techniques, postmortem imaging might provide new diagnostic possibilities which could also improve forensic reconstruction. The aim of this study was to determine the value of postmortem neck imaging in comparison to forensic autopsy regarding the
\end{abstract}

\author{
K. Yen $(\bowtie) \cdot$ M. J. Thali · E. Aghayev · C. Jackowski · \\ R. Dirnhofer \\ Institute of Forensic Medicine, \\ University of Bern, \\ Buehlstrasse 20, \\ 3012 Bern, Switzerland \\ e-mail: yen@irm.unibe.ch \\ Tel.: +41-31-6318411 \\ Fax: $+41-31-6313833$ \\ M. Sonnenschein \\ Institute of Diagnostic Radiology, \\ Inselspital Bern, \\ Freiburgstrasse 20, \\ 3012 Bern, Switzerland \\ C. Ozdoba \\ Department of Neuroradiology, \\ Inselspital Bern, \\ Freiburgstrasse, \\ 3010 Bern, Switzerland

\section{J. Weis} \\ Division of Neuropathology, \\ Institute of Pathology, \\ University of Bern, \\ Murtenstrasse 31, \\ 3010 Bern, Switzerland

\section{J. Weis} \\ Institute of Neuropathology, \\ University Hospital RWTH, \\ Aachen, Germany

\section{K. Zwygart} \\ Department of Clinical Research, \\ Magnetic Resonance Spectroscopy and Methodology, \\ University of Bern, \\ Switzerland
}

evaluation of the cause of death and the analysis of biomechanical aspects of neck trauma. For this purpose, 5 deceased persons ( 1 female and 4 male, mean age 49.8 years, range 20-80 years) who had suffered odontoid fractures or atlantoaxial distractions with or without medullary injuries, were studied using multislice computed tomography (MSCT), magnetic resonance imaging (MRI) and subsequent forensic autopsy. Evaluation of the findings was performed by radiologists, forensic pathologists and neuropathologists. The cause of death could be established radiologically in three of the five cases. MRI data were insufficient due to metal artefacts in one case, and in another, ascending medullary edema as the cause of delayed death was only detected by histological analysis. Regarding forensic reconstruction, the imaging methods were superior to autopsy neck exploration in all cases due to the post-processing possibilities of viewing the imaging data. In living patients who suffer medullary injury, follow-up MRI should be considered to exclude ascending medullary edema.

Keywords Odontoid fracture - Atlantoaxial distraction Computed tomography $\cdot$ Magnetic resonance imaging · Virtopsy

\section{Introduction}

Fractures of the odontoid process comprise $10-15 \%$ of all fractures of the cervical spine $[1,2]$ and are often caused by motor vehicle accidents or falls from a height. The incidence of craniocervical distractions is lower [1]. Saternus [3] found a complete distraction of the atlantoaxial ligaments with disruption of the medulla in 3\% of 427 cases of craniocervical trauma examined by autopsy. Traumatic brain stem lesions are frequently associated with craniocervical injuries; they are of great importance in forensic reconstruction aimed at elucidating the survival period as well as the cause of death [4-6].

In clinical practice, imaging techniques are routinely used for the examination of the craniocervical and cervico- 
thoracal region. In recent years digital imaging techniques such as computed tomography (CT) and magnetic resonance imaging (MRI) are increasingly replacing conventional radiographic applications as the gold standard for the assessment of the post-traumatized cervical spine [7-12].

In forensic cases, the autopsy procedure is often supplemented by plain radiographs which aid in the search for skeletal lesions. Alker et al. [13] reported 146 conventional postmortem x-ray examinations of head and neck trauma cases due to traffic accidents. The authors found neck injuries in $21 \%$ of the cases which were mostly localized at the cranio-cerebral junction, the atlas or axis, but the causes of death were not discussed. In a follow-up paper [14] in which a larger number of deceased persons were examined postmortem by conventional x-ray techniques, Alker et al. again did not focus on the cause of death. Shkrum et al. [15] and Cain et al. [16] used plain radiographs for the detection of head and neck injuries after fatal traffic accidents. Using the conventional x-ray technique, however, it is often difficult to detect fractures of the dens axis, because in the majority of cases open-mouth roentgenograms of the levels $\mathrm{C} 1$ and $\mathrm{C} 2[17,18]$ cannot be carried out due to postmortem rigor of the jaw musculature. Furthermore, the conventional x-ray technique is not well suited for the analysis of soft tissue or medullary lesions. Digital radiological imaging techniques such as $\mathrm{CT}$ and MRI have so far not been used in routine forensic diagnostics and studies have been limited to dissected upper spine specimens [19-21].

In the present study, multislice-computed tomography (MSCT) and MR imaging of the neck region, as an adjunct to forensic autopsy, are described in five cases who suffered odontoid fractures or craniocervical distractions. Specifically, we examined whether MSCT and MRI can aid in the forensic reconstruction and in establishing the cause of death.

\section{Cases}

A total of five victims who had suffered injuries of the cervicocranial region were examined ( 1 female and 4 males, mean age 49.8 years, range $20-80$ years). All the deceased were admitted to the institute of forensic pathology for autopsy examination and reconstruction of the sequence of events. All deceased underwent external examination of the bodies prior to scanning and autopsy by a forensic pathologist.

\section{Case 1}

A 32-year-old male who died on site in a motor vehicle accident after a frontal collision with a truck. Respiratory arrest occurred a few minutes after the incident following initial breathing activity, and there were no resuscitation attempts. The cause of death was blood aspiration in combination with air and fat embolisms.
Case 2

A 64-year-old woman who was hit by a car from the left when crossing the street as a pedestrian. Shortly after the accident the victim was responsive and tetraparesis was apparent but 4 days after the incident the woman died suddenly due to central respiratory arrest. In the meantime the medical situation had been stabile, although the patient had been unconscious. Ascending edema of the medulla oblongata had caused central respiratory arrest and therefore led to death; furthermore, a fat embolism worsened the respiratory status.

\section{Case 3}

An 80-year-old male was hospitalized after a fall down the stairs at home. A type II fracture of the odontoid process [22] was treated surgically 2 days after the accident by anterior screw fixation. A few hours after the operation, the man suddenly lost conciousness and suffered cardiac arrest; resuscitation was initially successful, but death occurred 2 days later and there had been no EEG activity in the meantime. Hypoxic brain damage due to postoperative cardiac arrest as a consequence of preexisting cardiac hypertrophy, severe coronary sclerosis and cardiac muscle fibrosis as well as fat embolism of the lung were considered to be the causes of death.

\section{Case 4}

A 20-year-old male was hit by a car from behind while riding his bicycle. Immediate death was due to transection of the medulla.

\section{Case 5}

A 53-year-old male who died immediately on site in a motor vehicle accident. Following a frontal collision the man was ejected from the vehicle and subsequently run over by a car. Death occurred due to transection of the brain stem.

\section{Methods}

The responsible justice department and the local ethics committee approved the present study.

\section{MSCT and MR imaging}

For MSCT and MR examination, the bodies were wrapped in two artefact-free body bags to prevent contamination of the scanners with blood or other materials and to guarantee anonymity of the deceased. MSCT imaging (GE Lightspeed QX/i unit; collimation of $4 \times 1.25 \mathrm{~mm}$ for a slice 
thickness of $1.5 \mathrm{~mm}$ ) and MRI scanning using a GE $1.5 \mathrm{~T}$ Signa Echospeed Horizon, version 5.8 unit (General Electric Systems, Milwaukee, WI) were performed prior to autopsy (mean time $28.4 \mathrm{~h}$ postmortem, range $15-50 \mathrm{~h}$ ). From the MSCT data, 2D and 3D reconstructions were calculated. The MR protocol included standard T2-weighted sequences (FSE, TR/TE 4000/90-105 ms) and T1-weighted sequences (SE, TR/TE 400/15-20 ms). The slice thickness was 2-4 mm with gaps of $0.2-1 \mathrm{~mm}$. Total MR neck examination time did not exceed 40-50 min.

The MSCT and MR imaging data were transferred to a workstation and the postprocessing was performed on a GE Advantage Windows workstation version 4.1 (GE medical systems, Milwaukee, WI) using software provided by the manufacturer.

\section{Autopsy}

After imaging (mean time $43.6 \mathrm{~h}$ postmortem, range 30 $70 \mathrm{~h}$ ), a standard forensic autopsy was performed according to current guidelines including special neck dissection techniques and histological examination (hematoxylineosin staining $\times 100-400$ after formalin fixation and embedding in paraffin). In cases 1 and 2 neck specimens were frozen and cut in a sagittal plane.

\section{Evaluation of the radiological and autopsy findings}

Evaluation of the imaging findings was performed by two radiologists independently. Both radiologists analyzed the imaging data retrospectively and with knowledge of the autopsy findings. Forensic pathologists carried out the autopsies, and a neuropathologist interpreted the histological specimens. The radiological findings were compared with the autopsy results. Forensic reconstruction of the incidents was done in close collaboration with the police.

\section{Results}

\section{Case 1}

Imaging MSCT displayed a type II fracture [22] of the odontoid process with a posterior displacement of $4 \mathrm{~mm}$ and a lateral displacement of $2.5 \mathrm{~mm}$ (Fig. 1A, B) and skull base fractures. Air was found intracranially and in the spinal canal. MR imaging revealed partial ablation of the posterior longitudinal ligament and hemorrhaging between the odontoid process and the ligament. The brain stem was intact (Fig. 1C).

Autopsy/histology A fracture of the odontoid process was apparent at autopsy. The dens was slightly displaced backward, the medulla oblongata was macroscopically intact and histological examination confirmed this finding (Fig. 1D). The skull base was extensively fractured, and the left
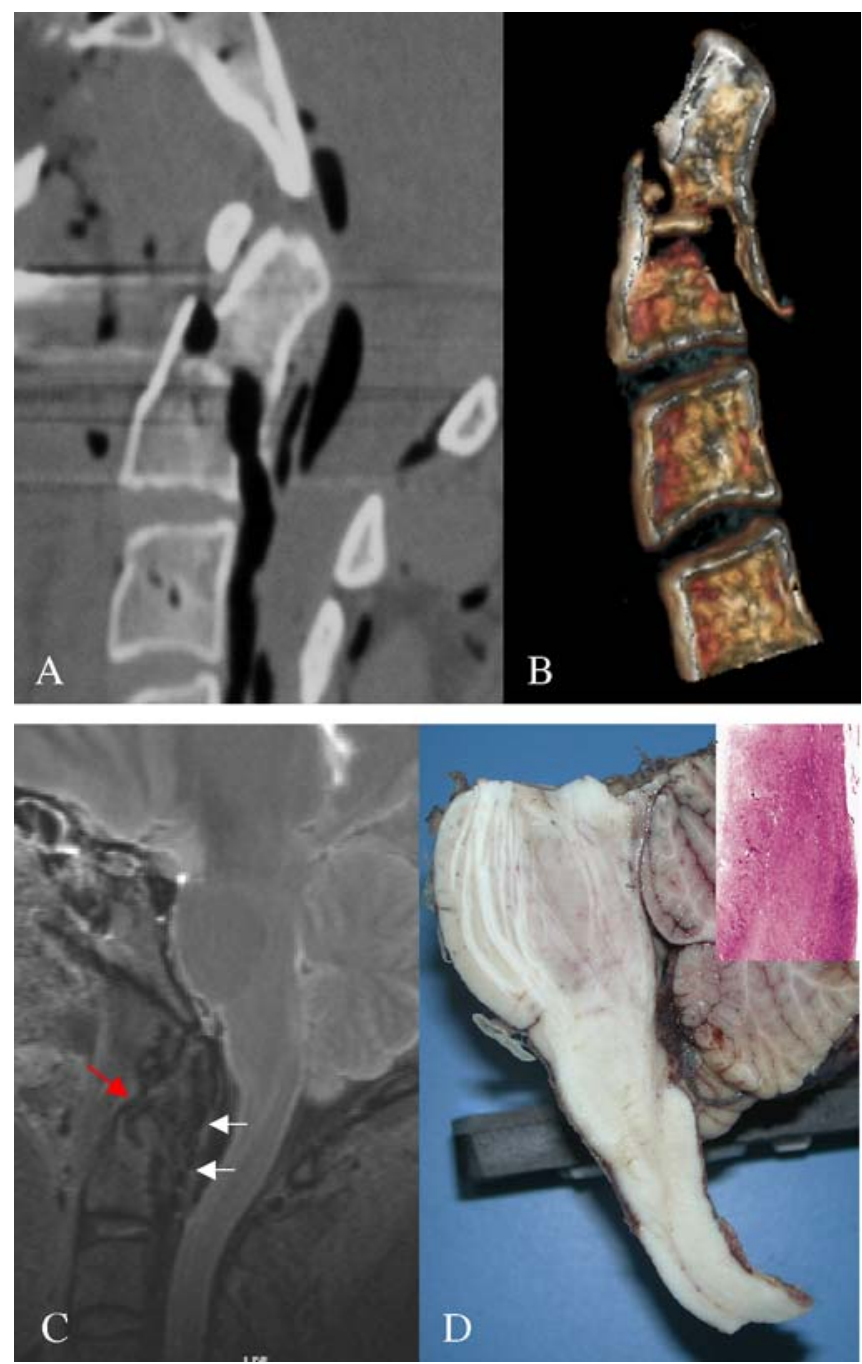

Fig. 1a-d Case 1: death in a motor vehicle collision (driver). Odontoid fracture type II (Andersen/D'Alonzo). A 2D reformatted MSCT scan showing the fracture of the odontoid. B Corresponding sagittal section through 3D volume-rendered MSCT data demonstrating the fracture site. C Sagittal T2-weighted fse MR image (TR 4000, TE 105) displaying the odontoid fracture (orange arrow) and partial ablation of the posterior longitudinal ligament (white arrows). D Sagittal section through the formalin-fixed brain stem. Upper right whole mount longitudinal paraffin section of the medulla. H\&E×3

parietal lobe showed fresh cortical and white matter injuries. There was marked cerebral edema.

Case 2

Imaging At MSCT a $4 \mathrm{~mm}$ posteriorly displaced type II dens fracture was found (Fig. 2A). MR imaging demonstrated spherical hemorrhage of the spinal cord at the fracture level (Fig. 2B). No signs of medullary edema were found.

Autopsy/histology A posteriorly displaced fracture of the odontoid process was seen at autopsy (Fig. 2C). The spinal cord presented with central spherical hemorrhage at the 

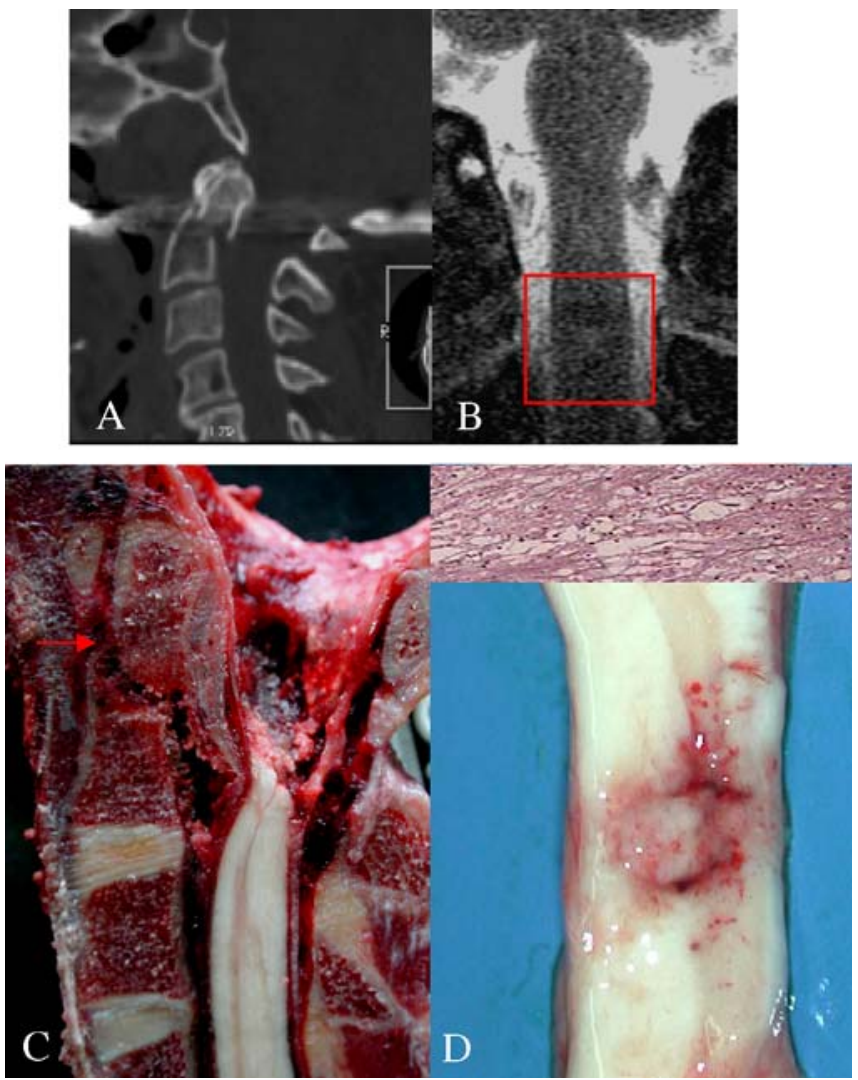

Fig. 2a-d Case 2: death of a pedestrian 4 days after being hit by a car. Odontoid fracture type II. A 2D reformatted MSCT image displaying the dens axis fracture. B Coronal T2-weighted fse MRI (TR 4000, TE 96,0). The central spinal cord hemorrhage presents as hyperintense roundish signal alteration (inset). C Sagittal cut through neck specimen showing posteriorly displaced odontoid fracture (arrow). At autopsy, the spinal cord has been transected approximately at the fracture level. D Sagittal section through the medulla oblongata/spinal cord transition demonstrating prominent hemorrhage at the fracture level. Above Edema of the white matter of the medulla oblongata above the hemorrhage. Paraffin section, $\mathrm{H} \& \mathrm{E} \times 150$

fracture level (Fig. 2D). Histological examination revealed medullary and upper spinal cord edema as well as central hemorrhagic necrosis of the tissue below the medullaspinal cord transition (Fig. 2D).

\section{Case 3}

Imaging MSCT examination revealed a surgically treated type II fracture of the odontoid. The screw was positioned accurately (Fig. 3). No hemorrhagic alterations were present. Due to metal artefacts resulting from the surgical screw fixation, MR imaging could not be used for brain stem and spinal cord tissue examination.

Autopsy/histology The brain was edematous and showed recent necrosis in the parietal and occipital lobes as well as in the tonsillary region. The operation site did not show any signs of postoperative bleeding or infection, the posi-

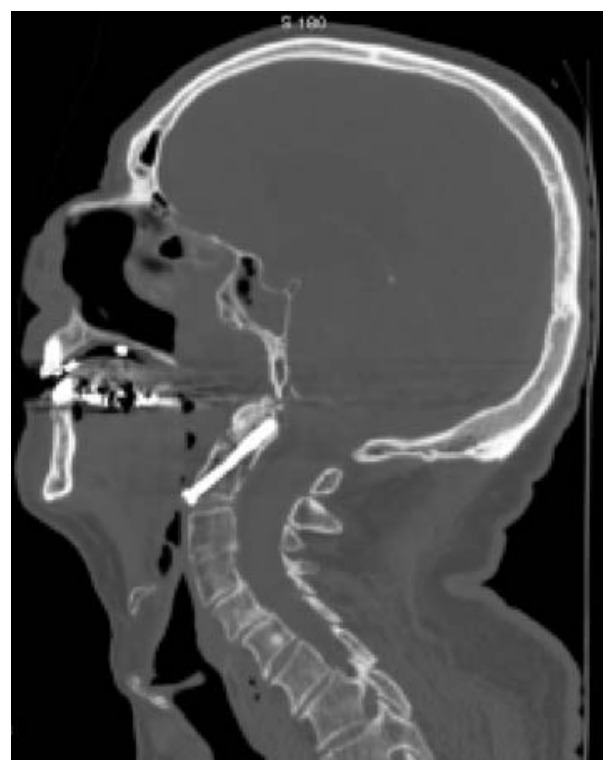

Fig. 3 Case 3: fall down stairs. Odontoid fracture type II after surgical treatment. The screw is in a correct position in the reformatted 2D MSCT image

tion of the screw was correct with sound fixation of the fracture. The spinal cord and the brain stem were without pathological findings.

Case 4

Imaging A dislocation of the craniocervical joint was clearly visible in the MSCT scans (Fig. 4A). The odontoid process showed posterior displacement of approximately $20 \mathrm{~mm}$ and slight lateral displacement to the right. No fractures of the cervical vertebrae were apparent. MRI depicted the dislocation with the accompanying ligamentous injuries and the avulsion of the spinal cord (Fig. 4B). Brain stem and medulla oblongata showed no signs of hemorrhage or edema. Subarachnoid hemorrhage was found covering the brain and the anterior spinal cord meninges.

Autopsy/histology Autopsy revealed dislocation of the joint between the first and second cervical vertebrae associated with rupture of the posterior longitudinal and transverse ligaments and a complete transection of the spinal cord approximately $2 \mathrm{~cm}$ below the medulla oblongata. The cerebrum, cerebellum and the anterior brain stem were covered by subarachnoid hemorrhages. Intracranially, a thin subdural blood layer was present covering both hemispheres. There were small parietal and frontobasal foci of cortical contusion.

\section{Case 5}

Imaging MSCT revealed subluxation of the cranial cervical junction (Fig. 5A). The scans also depicted extensive skull and skull base fractures and air in the spinal canal 

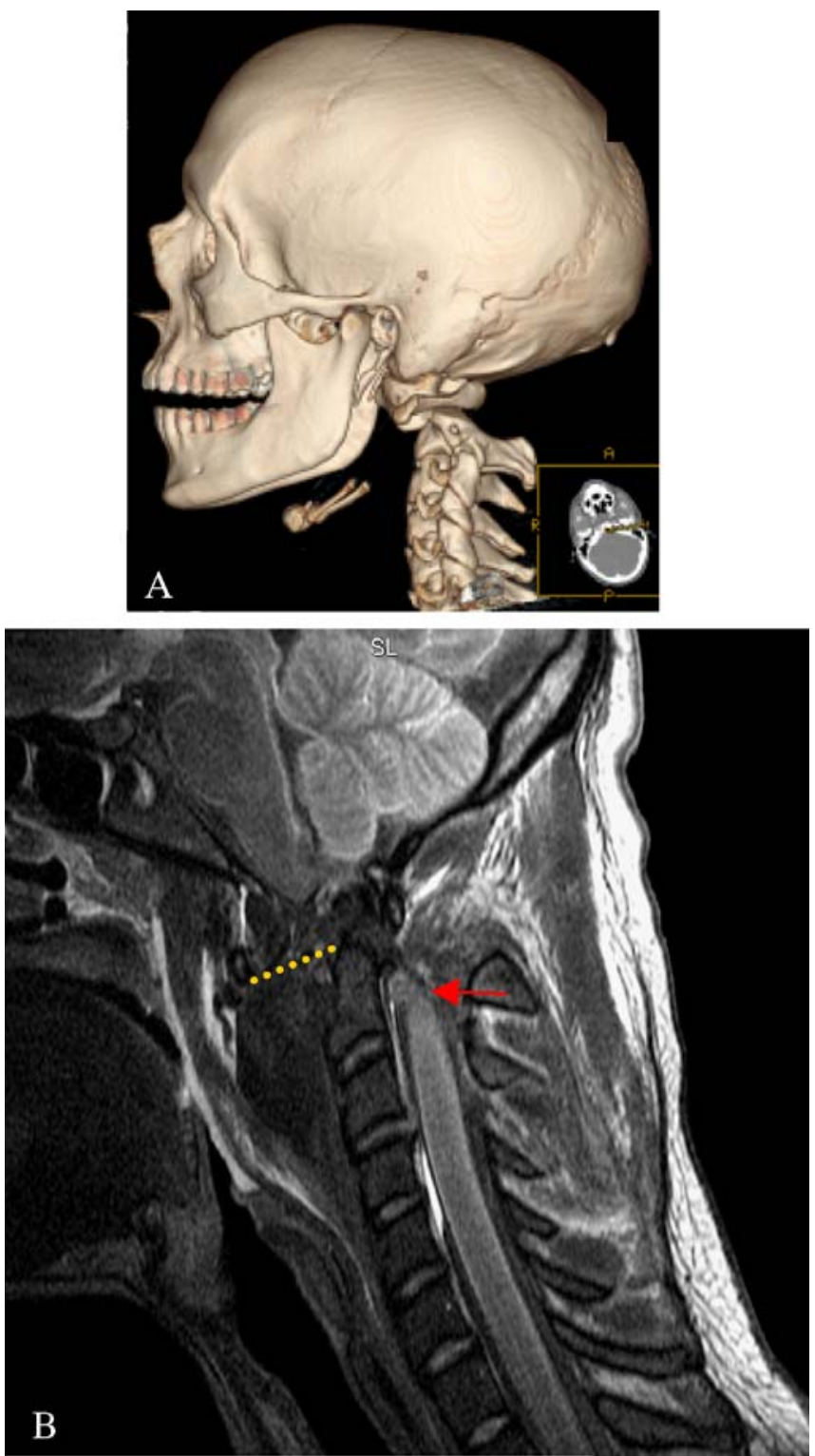

Fig. 4a-b Case 4: atlantoaxial distraction in a cyclist who was hit by a car from behind. A The luxation is well illustrated in the 3D volume rendered MSCT image. B Sagittal T2-weighted MR image (TR 4540, TE 90,0) demonstrating posterior displacement of the dens axis with a distance between the anterior arch and the odontoid process of $20.5 \mathrm{~mm}$ (dashed line). The transection of the spinal cord is indicated by an arrow. Subarachnoideal hemorrhage covering the anterior medulla oblongata and spinalis

as well as intracranially. The medullary rupture was easily detectable by MRI. No bleeding or edema of the brain stem tissue could be seen in the MR scans (Fig. 5B).

Autopsy/histology At autopsy, the medulla was found to be completely ruptured at the level of the olivary nuclei, parts of the cerebellum and the cerebrum were destroyed. No intraparenchymal hemorrhage was present in the vicinity of the rupture. The atlantoaxial luxation was not diagnosed using autopsy methods. The skull base and the left temporal and parietal bone were fractured.
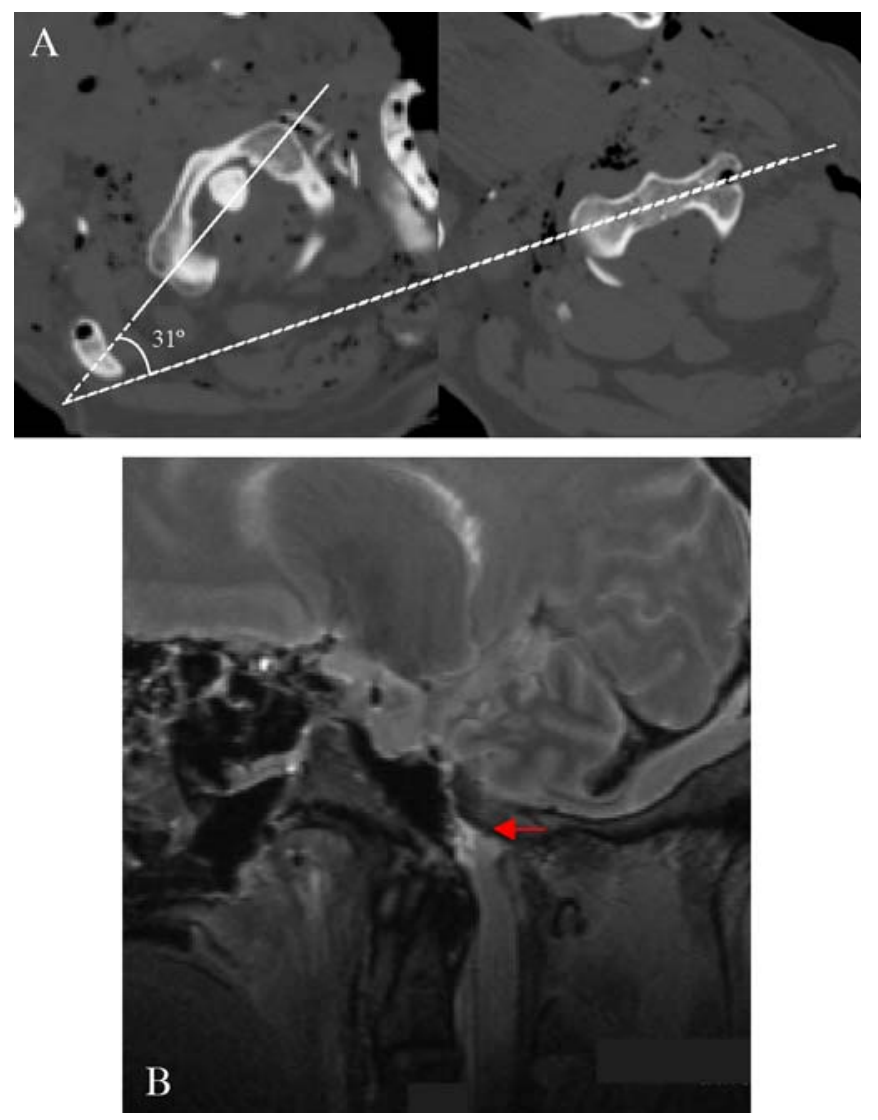

Fig. 5a-b Case 5: car driver who suffered an atlantoaxial distraction with medullary transection in a frontal collision in which he had been ejected and subsequently run over by a car. A Two axial MSCT slices (left level of the atlantic body, right corpus axis level) are presented side by side. In contrast to autopsy, the incomplete luxation of the atlantoaxial junction is striking in the MSCT examination. B Medullary transection (arrow) is well depicted in the sagittal T2-weighted MR image (TR 4000, TE 105)

\section{Discussion}

Traumatic injuries of the craniocervical region are probably underdiagnosed as many casualties do not undergo forensic examination including autopsy. Even if an autopsy is performed, lesions of the dorsal neck region might be overlooked as the dissection of that location is difficult as the examination is intricate [23-25] and not routinely carried out. Dorsal neck dissection techniques are vastly invasive, and when the upper spine is extracted the corpse is less well preserved than after a routine autopsy. In certain cases bone maceration techniques have to be applied which require hours to days, thus extending the examination. As an adjunct to these methods, Unterharnscheidt [26] and Bratzke [4] have already discussed the increasing importance of radiological imaging techniques in forensic cases with brain stem and spinal column lesions. In the present study, osseous injuries of the upper spine and head were depicted reliably and in detail by MSCT in all cases (Figs. 1A, B, 2A, 3, 4A, 5A), even in the post-surgical situation (case 3 ). The cranial cervical displacement in cases 4 and 5 were displayed especially well 
in the 3D reconstructed images. Additionally, MSCT revealed air in the spinal canal in cases with an open fracture of the skull (cases 1 and 5). However, MSCT did not depict small hemorrhages, contusions or necroses of the brain or spinal cord.

For radiological imaging of traumatic brain stem and spinal cord lesions, MRI has proven to be the best method $[27,28]$. In clinical emergencies, however, MRI cannot be used in all cases because the examination is time-consuming and complex. In contrast, postmortem examination is feasible with reasonable effort [29]. In case 1, MRI depicted the intact brain stem and upper spinal cord in spite of a posteriorly displaced odontoid fracture as well as the partial ablation of the posterior longitudinal ligament (Fig. 1C). Case 2 was showing medullary hemorrhage which was located at the level of the dens axis fracture (Fig. 2B). As already depicted in the MSCT scans, the odontoid process was also displaced in a posterior direction in this case. In case 3, the evaluation of the MRI findings was complicated due to artefacts caused by the metal screws and parts of the CNS were completely superimposed by these artefacts. On the other hand, the medullary transection in both cases 4 and 5 was again well detectable in the MR examination (Figs. 4B and 5B).

\section{Forensic reconstruction}

In case $1 \mathrm{a}$ frontal impact caused translational head trauma. No rotational force had been applied to the head. The osseous injuries were detected in the MSCT images including 2D and $3 \mathrm{D}$ reconstructions and were concordant with the trauma mechanism. Posterior displacement of the dens axis was also seen in the neck specimen that had been prepared at autopsy. There, the fracture site was displayed only in one plane, and the preparation had been laborious and time-consuming. In case 2 , a combination of translational and rotational forces due to the vehicle impact, the loading of the body on the vehicle and the subsequent impact on the street surface led to the posteriorly displaced odontoid fracture. The radiological findings (including forensic analysis of the skull fracture system and soft tissue injuries) were in line with the presumed trauma mechanism. Again in this case autopsy evaluation was more intricate due to the complexity of the neck dissection and preparation of the neck specimen, and due to the fact that the process of autopsy resulted in partial destruction of the tissues and bones investigated. Surgical treatment of the odontoid fracture in case 3 led to alterations at the fracture site which caused artefacts in MSCT and MR imaging. Relating to the clinical data and to the imaging findings, the neck injury was concordant with an injury due to rotational forces to the head when falling down the stairs. In case 4, again, a combination of translational and rotational forces caused atlantoaxial displacement. Here, imaging methods were far superior to autopsy in detecting the neck injuries as the post-processed pictures could be turned in each direction and viewed in all planes. The distortion of $\mathrm{C} 1$ and $\mathrm{C} 2$ was well displayed in the volume-rendered MSCT scans, whereas the detection was complex using autopsy findings. The same was true for case 5; here, a partial displacement of the atlantoaxial joint had been overlooked in the autopsy examination, whereas MRI and-even more clearly-MSCT depicted the cervical column injury. Forensic reconstruction established that the lateral displacement of the head was caused when the victim was run over by a car.

\section{Cause of death}

In cases 4 and 5 , the causes of death could be determined before autopsy by radiological imaging (Figs. 4A, B and 5A, B); both victims had suffered immediate death at the accident site, and radiological pre-autopsy MSCT and MR examination had revealed the fatal medullary lesions. Imaging of the thorax and abdomen revealed no injuries resulting in immediate onset of death. In case 3, the postoperative alignment of the occipital cervical spine was well-illustrated with MSCT (Fig. 3), whereas MR imaging was not suitable for CNS and soft tissue diagnosis due to the metal artefacts. However, MSCT revealed no pathological postoperative alterations. Case 1 showed an intact brain stem and spinal cord tissue in face of the presence of an odontoid fracture. Considering these findings, and in accordance with the clinical course, the craniocervical lesions were not responsible for the death of the person. Compared to autopsy, the relevant neck findings in this case could be equally well established by imaging methods (Fig. 1A-D).

\section{Ascending collateral medullary edema}

The situation was more difficult in case 2 ; here, medullary hemorrhage was detected by MRI before autopsy (Fig. 2B). The location of the hemorrhage in the upper spinal cord indicated the primary genesis of that lesion. As known from clinical data, the woman had presented with tetraplegia upon admission to the hospital; the initial spinal cord trauma was thus affirmed. However, the injuries in the brain stem region did not cause immediate death; the patient died 4 days after the incident. Using MSCT and MRI, which had been performed without edema-sensitive stir-sequences, the medullary edema that was responsible for central respiratory arrest was not diagnosed. Even macroscopical inspection at autopsy did not establish the cause of death, whereas histological examination revealed distinct collateral ascending edema of the medulla oblongata (Fig. 2D) and explained the clinical outcome.

This example shows that radiological imaging in forensic medicine has to be supplemented by careful tissue sampling to facilitate further examination. For this purpose, minimally invasive autopsy techniques have to be developed. In addition, micro-CT and micro-MR techniques might aid in the detection of alterations on the histological level. 
Collateral ascending medullary edema in a person who had suffered traumatic medullary injury, as seen here in case 2, was first described by Dirnhofer et al. [6]. Edema ascending to the respiratory and circulatory centers located in the brain stem might lead to death of the patient. Ascending edema could explain the sometimes surprising onset of death in patients who have suffered odontoid fractures and were treated for several days without major complications. Therefore, in the clinical management of odontoid fractures follow-up MR examinations of the brain stem to rule out serious complications due to posttraumatic edema of the medullary tissue should be considered. In the cases of the present series, no stir-sequences were used during the MR examination. As these reliably detect edema of CNS and other tissues, both postmortem MR imaging and imaging in the living should include these sequences in such cases.

As shown in the present study, both MRI and MSCT offer new, non-invasive diagnostic possibilities in the postmortem examination of the injured craniocervical region. Because motion artefacts are absent and examination times are basically unrestricted, the quality of the imaging is often superior to the results achieved in clinical practice. The head and neck scans are obtained within a time span of $1-2 \mathrm{~h}$, if both imaging modalities are applied; MSCT alone requires only a few minutes. The radiological data can be used for 2D and 3D reconstructions which can be stored indefinitely, viewed in all planes and turned in every direction, thus offering excellent possibilities for the forensic reconstruction. The digitally stored images can easily be sent for outside review which might be advantageous especially in the case of uncommon lesions, and, finally, case-relevant "virtual" findings can be demonstrated in court or in the classroom, whereas autopsy images are not readily presentable to the public.

In conclusion, MSCT and MRI appeared to be helpful in the postmortem forensic evaluation of injuries of the craniocervical region. In the presented cases the imaging methods were practicable with reasonable effort. Forensically relevant issues such as the cause of death or the evaluation of traumatic injuries were sufficiently covered by radiological methods, and the possibility of $2 \mathrm{D}$ and $3 \mathrm{D}$ image data processing significantly faciliated forensic reconstruction of the course of events.

Acknowledgments The authors would like to thank Roland Dorn, Urs Koenigsdorfer and Therese Perinat for their excellent technical assistance and Verena Beutler, Elke Spielvogel, Carolina Dobrowolska and Christoph Laeser for their help with data acquisition. The research was supported by grants from the Gebert-RuefFoundation, Basel, Switzerland, and from the Government of Vorarlberg, Bregenz, Austria.

\section{References}

1. Unterharnscheidt F (1992) Die kraniozervikale Uebergangsregion. In: Doerr W, Seifert G, Uehlinger E (eds) Pathologie des Nervensystems VII. Springer, Heidelberg, pp 107-184
2. Ryan MD, Henderson JJ (1992) The epidemiology of fractures and fracture-dislocations of the cervical spine. Injury 23:38-40

3. Saternus KS (1979) Die Verletzungen von Halswirbelsäule und von Halsweichteilen. In: Junghanns H (ed) Die Wirbelsäule in Forschung und Praxis. Hippokrates, Stuttgart

4. Bratzke H (1984) Zur Morphologie der traumatischen Hirnstammschädigung (biomechanische und differential diagnostische Aspekte). Zentralbl Rechtsmed 26:205-222

5. Dirnhofer R, Patscheider H (1977) Zur Entstehung von Hirnstammverletzungen. Z Rechtsmed 79:25-45

6. Dirnhofer R (1975) Zur Ueberlebenszeit bei primarer traumatischer Hirnstammschaedigung. Z Rechtsmed 77:65-78

7. Blacksin MF, Lee HJ (1995) Frequency and significance of fractures of the upper cervical spine detected by CT in patients with severe neck trauma. AJR Am J Roentgenol 165:12011204

8. Kaiser JA, Holland BA (1998) Imaging of the cervical spine. Spine 23:2701-2712

9. Link TM, Schuierer G, Hufendiek A, Horch C, Peters PE (1995) Substantial head trauma: value of routine CT examination of the cervicocranium. Radiology 196:741-745

10. Imhof H, Fuchsjager M (2002) Traumatic injuries: imaging of spinal injuries. Eur Radiol 12:1262-1272

11. Weisskopf M, Reindl R, Schroder R, Hopfenmuller P, Mittlmeier T (2001) CT scans versus conventional tomography in acute fractures of the odontoid process. Eur Spine J 10:250 256

12. Deliganis AV, Baxter AB, Hanson JA, Fisher DJ, Cohen WA, Wilson AJ, Mann FA (2000) Radiologic spectrum of craniocervical distraction injuries. Radiographics 20 Spec No:S237250

13. Alker GJ, Oh YS, Leslie EV, Lehotay J, Panaro VA, Eschner EG (1975) Postmortem radiology of head and neck injuries in fatal traffic accidents. Radiology 114:611-617

14. Alker GJ Jr, Oh YS, Leslie EV (1978) High cervical spine and craniocervical junction injuries in fatal traffic accidents: a radiological study. Orthop Clin North Am 9:1003-1010

15. Shkrum MJ, Green RN, Nowak ES (1989) Upper cervical trauma in motor vehicle collisions. J Forensic Sci 34:381-390

16. Cain CM, Ryan GA, Fraser R, Potter G, McLean AJ, McCaul K, Simpson DA (1989) Cervical spine injuries in road traffic crashes in South Australia, 1981-86. Aust N Z J Surg 59:15-19

17. Ehara S, el-Khoury GY, Clark CR (1992) Radiologic evaluation of dens fracture. Role of plain radiography and tomography. Spine 17:475-479

18. Ellis GL (1991) Imaging of the atlas (C1) and axis (C2). Emerg Med Clin North Am 9:719-732

19. Obenauer S, Herold T, Fischer U, Fadjasch G, Koebke J, Grabbe E, Saternus KS (1999) The evaluation of experimentally induced injuries to the upper cervical spine with a digital $\mathrm{x}$-ray technic, computed tomography and magnetic resonance tomography. Rofo Fortschr Geb Rontgenstr Neuen Bildgeb Verfahr 171:473-479

20. Willauschus WG, Kladny B, Beyer WF, Gluckert K, Arnold H, Scheithauer R (1995) Lesions of the alar ligaments. In vivo and in vitro studies with magnetic resonance imaging. Spine 20 : 2493-2498

21. Stabler A, Eck J, Penning R, Milz SP, Bartl R, Resnick D, Reiser M (2001) Cervical spine: postmortem assessment of accident injuries - comparison of radiographic, MR imaging, anatomic, and pathologic findings. Radiology 221:340-346

22. Anderson LD, D'Alonzo RT (1974) Fractures of the odontoid process of the axis. J Bone Joint Surg Am 56:1663-1674

23. Leditschke J, Anderson RM, Hare WS (1992) The cervical spine in fatal motor vehicle accidents. Clin Exp Neurol 29:263271

24. Saternus KS (1988) Examination of the spine within the scope of the forensic autopsy. Beitr Gerichtl Med 46:489-495

25. Sim E, Berzlanovich A (1996) Fatal transdental posterior rotary subluxation of the cervical spine. A case report. Spine 21:15781583 
26. Unterharnscheidt F (1992) Bedeutung der Computertomographie fuer die Diagnose von Frakturen und Dislokationen posttraumatischer Schaeden an Wirbelsaeule und Rueckenmark. In: Doerr W, Seifert G, Uehlinger E (eds) Pathologie des Nervensystems VII. Traumatologie von Hirn und Rueckenmark. Springer, Heidelberg, pp 618-621

27. Firsching R, Woischneck D, Klein S, Ludwig K, Dohring W (2002) Brain stem lesions after head injury. Neurol Res 24:145146
28. Shibata Y, Matsumura A, Meguro K, Narushima K (2000) Differentiation of mechanism and prognosis of traumatic brain stem lesions detected by magnetic resonance imaging in the acute stage. Clin Neurol Neurosurg 102:124-128

29. Thali MJ, Yen K, Schweitzer W et al. (2003) Virtopsy, a new imaging horizon in forensic pathology: virtual autopsy by postmortem multislice computed tomography (MSCT) and magnetic resonance imaging (MRI) - a feasibility study. J Forensic Sci 48:386-403 